\title{
JUURNAL_RU
}

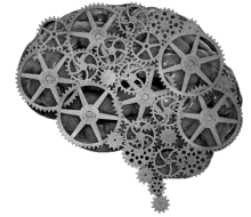

COMPANY GROUP "INTELLEKT"

\author{
Семенова А.А. \\ НИ МГУ им. Н. П. Огарёва \\ Саранск, Россия
}

doi: 10.18411/lj2016-3-75

\section{Исследование механизма влияния института государственной собственности на экономическое развитие регионов}

Отношения собственности занимают в региональной структуре особое место. Экономическое развитие региона и возможности управления комплексным развитием находятся в непосредственной зависимости от эффективности использования располагаемым имуществом органами власти субъекта Российской Федерации.

Формирование и развитие отношений собственности играют ключевую роль в регламентации взаимоотношений экономических субъектов. Актуальность исследования изменений, происходящих в институте собственности в современных условиях, определяется следующими основными процессами: переходным характером всего мирового сообщества и происходящими при этом процессами постиндустриальной трансформации отношений собственности; особенностями периода кризисных явлений и реформирования экономик, в процессе которых проблемы разгосударствления и оптимального соотношения различных форм собственности, безусловно, занимают центральное место. При этом все эти вопросы затрагивают государственную собственность как одну из ее форм, и являются ключевыми для исследования механизма ее влияния на развитие экономики.

Необходимым условием реализации регионами и государством в целом своих функций является наличие в их собственности определенного объема 
материальных и финансовых ресурсов. При этом масштабы государственной собственности, ее структура и формы использования в результате воздействия на экономику не являются раз и навсегда заданными. Так, после процессов приватизации 1990-х г. доля государственной собственности в нашей стране уменьшилась, однако государство и по сей день играет важную роль в системе экономических отношений собственности. Немаловажная роль также отдана регионам и региональным органам власти, которые, в соответствии с Гражданским кодексом РФ, также являются полноправными собственниками имущества в связи с разделением государственной собственности на федеральную и собственность субъектов РФ.

Важным фактором экономического процветания регионов является создание благоприятного климата для формирования крупных хозяйствующих субъектов. Данные хозяйственные структуры могут стать надежной опорой регионов при решении таких задач, как подъем экономики; структурная перестройка экономики регионов; повышение конкурентоспособности отечественного производства. Особую значимость данных структур определяет то, что они необходимы для сохранения существующего промышленного потенциала регионов, увеличения возможностей выхода на мировые рынки, особенно в части выпуска наукоемкой продукции.

Сегмент государственной собственности субъектов РФ, представленный предприятиями, составляя незначительную долю в общем количестве предприятий, занимает однако отнюдь не последнее место по возможностям своего воздействия на экономику и по значимости для общественного воспроизводства. Опыт функционирования государственных предприятий показывает, что используемый как клише тезис об их изначально меньшей эффективности по сравнению с частными далеко не бесспорен.

Стоит отметить, что государственные предприятия при прочих равных условиях имеют некоторые преимущества над частным сектором. Они устанавливают более низкие цены на свою продукцию; имеют большие 
мощности, чем это необходимо; больше средств тратят на строительство зданий и помещений; используют более капиталоемкие технологии; реже пересматривают цены, слабее реагируют на изменения в спросе; имеют более продолжительные сроки службы высших управляющих [1]. В целом данные преимущества носят позитивный характер для населения регионов, а оно как раз и является основным потребителем товаров и услуг, реализуемых государственными предприятиями и учреждениями. Следовательно, налицо получение и социального эффекта.

Сравнивая долю государственных российских компаний и организаций (рис. 1) в национальной экономике в различные исторические периоды и на современном этапе, можно заметить тенденцию к снижению абсолютного количества таких предприятий, однако начиная с 2000-х годов темпы сокращения все же значительно снизились.

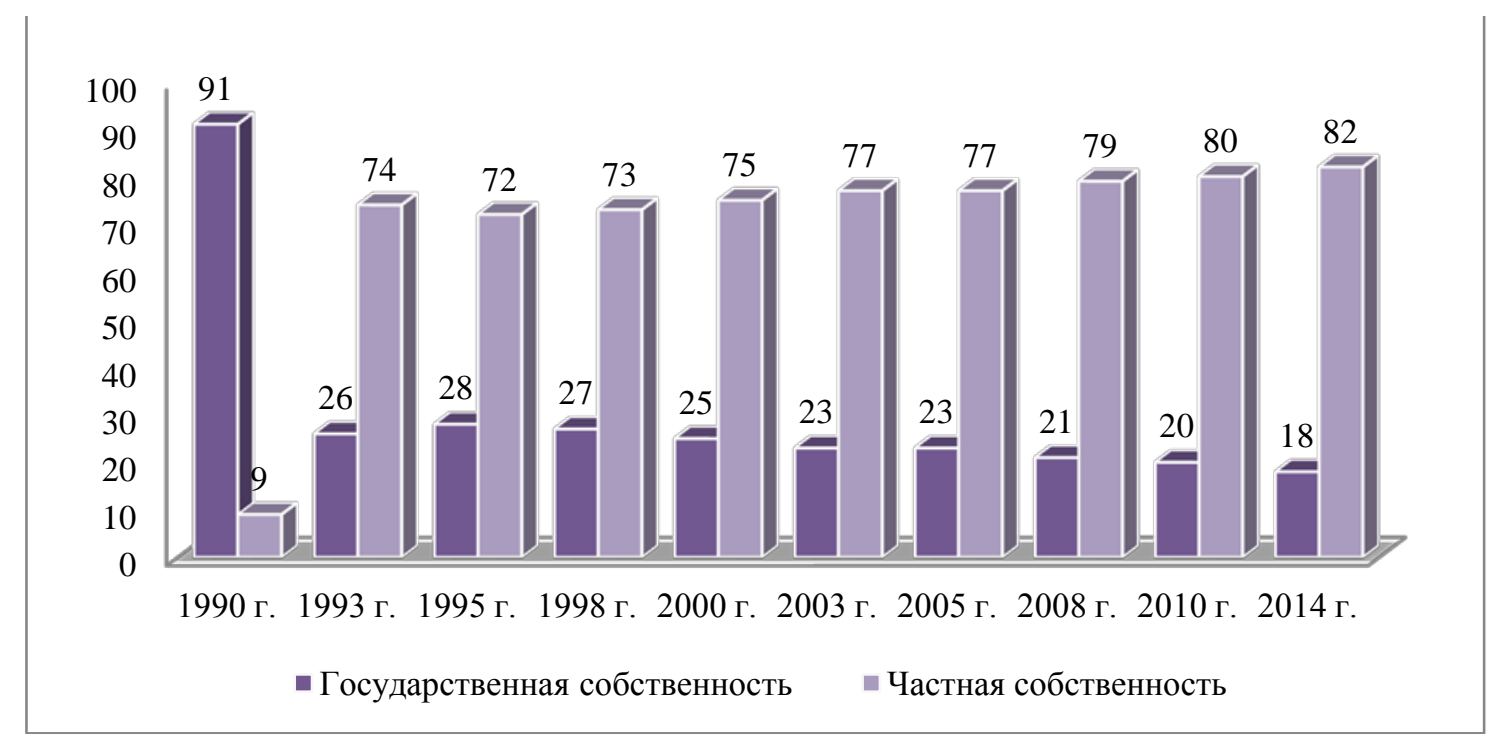

Рис. 1 Динамика соотношения государственной и частной форм собственности в РФ, в \% к общему числу

В результате процессов приватизации, начатых еще в 1990-х годах, в частные руки перешло около $74 \%$ всех государственных предприятий, на которых работали почти $70 \%$ занятых. Реализация долгосрочных планов приватизации направлена как на снижение общего количества государственных предприятий, так и на минимизацию доли государства в ведущих компаниях до уровня ниже контрольного пакета акций. Исключением должны стать только те 
организации, которые имеют стратегическое значение для страны, или те, деятельность которых непосредственно направлена на обеспечение безопасности. Вырученные в ходе приватизации средства предполагается направлять на финансирование социальных обязательств и на улучшение макроэкономической конъюнктуры.

В настоящее время 60 компаний с государственным участием реализуют программы инновационного развития, в том числе 47 компаний - начиная с 2011 года, еще 13 - начиная с 2012 года. Данные компании обеспечивают около трети российского промышленного производства, формируют около 20\% ВВП. Численность занятых в данных компаниях составляет около 4 млн. чел. По оценке Минэкономразвития России общий прогнозируемый объем инвестиций госкомпаний в инновационное развитие экономики на 2011-2015 гг. - около 6 трлн. руб., в том числе около 70\% - из внебюджетных источников [2]. Государство надеется, что такие меры вызовут двойной эффект. С одной стороны, усиление конкуренции в том секторе заставит другие предприятия интенсивнее инвестировать в новые технологии и модернизацию производства. С другой стороны, увеличение совокупного спроса на инновационные решения подтолкнет совокупное предложение со стороны бизнеса, научных предприятий и высших учебных заведений. Исходя из этого, в силу значимости государственных предприятий для экономического развития территории представляется невозможным их дальнейший переход в частные руки.

Однако анализ показывает, что на протяжении всего периода экономических реформ основные усилия государства концентрируются не на обеспечении повышения отдачи от использования государственной собственности, а на выполнении функций ее распределения. Органами государственной власти распределяются лицензии на разработку месторождений полезных ископаемых, частичные права собственности в виде различного рода квот, реализуются объекты государственной собственности в порядке ее приватизации. В то же время государство неоправданно мало уделяет 
внимания таким имеющим приоритетное значение функциям управления государственной собственностью как обеспечение ее сохранности, еe воспроизводства, эффективности ее использования, обеспечение реализации государственных интересов.

Логика государственного регулирования в сфере управления государственной собственностью предполагает, что именно эти функции должны быть в центре внимания органов государственной власти, а их деятельность по обеспечению эффективности использования и сохранности государственной собственности, несмотря на ее большую трудоемкость по сравнению с распределительными функциями, должна стать доминирующей в процессе управления [3]. Суть данных преобразований, по моему мнению, должна заключаться в пересмотре самой концепции управления государственной собственностью. На смену устремлениям к приватизации должна прийти более обоснованная и дальновидная стратегия превращения объектов государственной собственности в действенный рычаг стабилизации и подъема производственной экономики. Поскольку объекты государственной собственности субъектов РФ пока еще в меньшей мере поглощены волной приватизации по сравнению с объектами федеральной собственности, то применение такой концепции на региональном уровне наиболее актуально. Данный ориентировочный подход в управлении имуществом субъекта Российской Федерации ведет к снижению возможностей быстрого получения доходов от приватизации в региональный бюджет. Однако он позволит обеспечить высокую бюджетную эффективность за более продолжительный отрезок времени, что будет свидетельствовать о более высоких темпах экономического роста.

Опираясь на вышесказанное, можно выделить основнье фрункции государственной собственности, характеризующие направления ее воздействия на экономическое развитие регионов (рис. 2). 


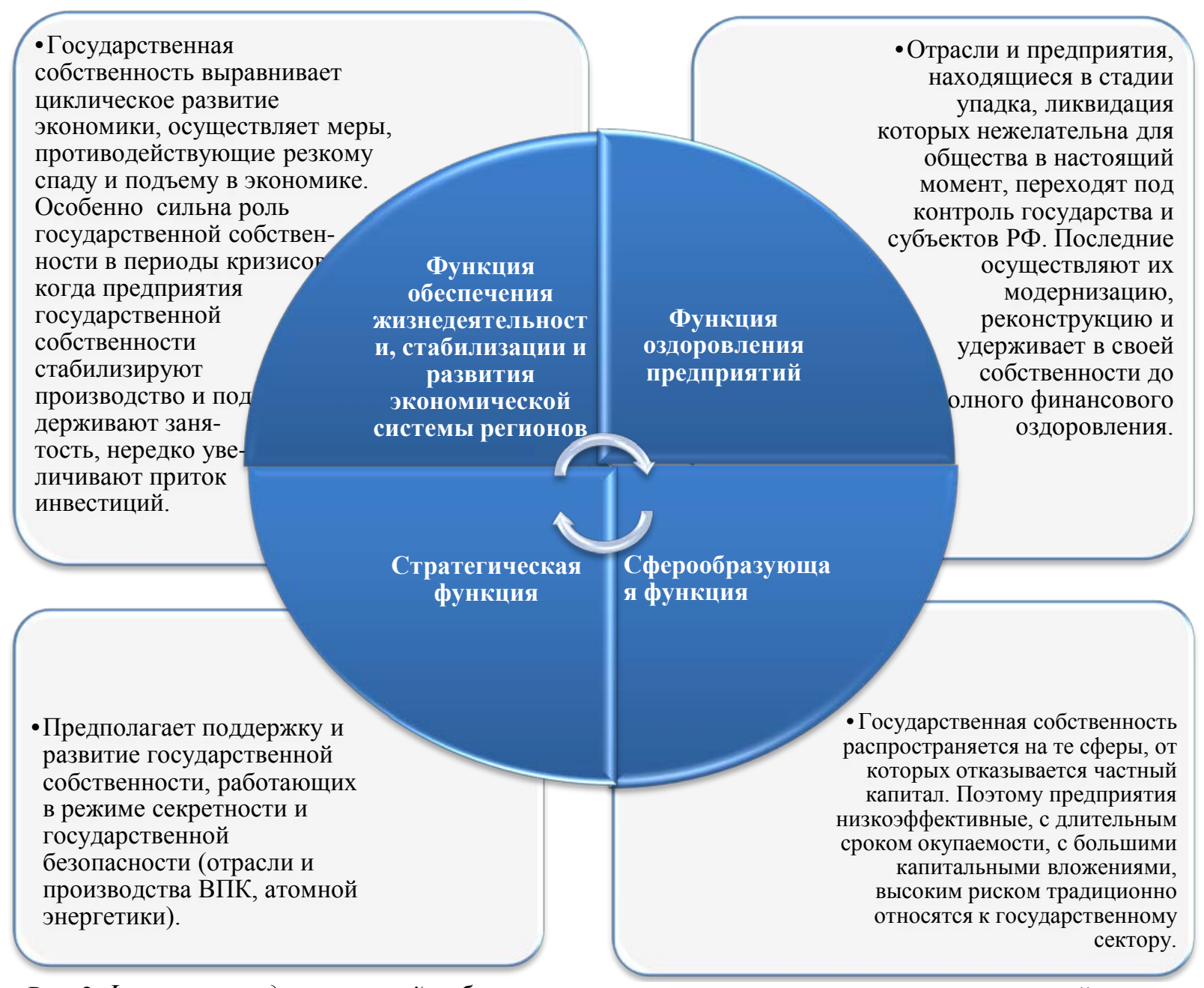

Рис. 2 Функиии государственной собственности, характеризующие направления ее воздействия на экономическое развитие регионов

Структура государственной собственности субъекта РФ определяется как раз теми функциями, которые она выполняет в процессе общественного воспроизводства. В еe составе представлены практически все элементы национального богатства: природные ресурсы, земля, имущественные комплексы предприятий, учреждения и организации, пакеты акций акционерных обществ и другие. Как мы видим, в собственности государства и субъектов находятся уникальные материальные ресурсы, уже формирующие базовые предпосылки экономического роста.

Подводя итог вышесказанному, подчеркнем, что важное значение для $\begin{array}{llllll}\text { экономического } & \text { развития регионов } & \text { имеет } & \text { соотношение } & \text { масштабов } \\ \text { государственной } & \text { собственности и еe } & \text { реально имеющегося потенциала. }\end{array}$ 
Неэффективно используемые государственные ресурсы разрушают имеющийся региональный потенциал государственной собственности и снижают доходы в бюджет. Это приводит не только к дефициту региональных бюджетов, но и к разрушительным процессам национального богатства нашей страны. Поэтому основной задачей федеральных органов власти и органов власти субъектов РФ на современном этапе развития имущественных отношений является реализация потенциала государственной собственности в степени, приближенной к максимальному значению: вовлечение всех объектов государственного имущества в хозяйственный оборот и поиск наилучших средств и способов их использования для обеспечения экономического развития.

\section{Литература:}

1. Авеков В.В. Актуальные вопросы управления собственностью субъекта Федерации: монография / под научн. ред. д.э.н., проф. Б.А. Райзберга. М.: Маросейка, 2010.-283 с.

2. Официальный сайт Федеральной службы государственной статистики [Электронный pecypc]. - Режим доступа : http://mrd.gks.ru/ (дата обращения - 21.03.2015).

3. Кочеткова С.А. Концептуальная модель управления региональной собственностью / С.А. Кочеткова // Современные проблемы науки и образования. - 2012. - № 2. 